\title{
Desenvolvimento de Habilidades Tecnológicas como Ferramenta de Qualificação para a Comunidade Migrante da Cidade de Rio Grande/RS
}

\author{
Fernanda P. Mota $^{1}$, Janaina A. da Silva ${ }^{1}$, Diana F. Adamatti ${ }^{1}$ \\ ${ }^{1}$ Centro de Ciências Computacionais - Universidade Federal do Rio Grande (C3/FURG) \\ Rio Grande - RS - Brazil \\ \{nandapm2010, janaina.adolfo.ds, dianaada\}@gmail.com
}

\begin{abstract}
Computational thinking contributes to the development of the individual's adjacent skills. In our research, computational thinking can be seen as a means to assist in the process of solving problems and learning about the use of technology. This work has as main objective to propose the use of computational tools for the training of the migrant population of Haitian and Senegalese origin in the city of Rio Grande / RS. The results of this study allowed us to observe the progress of students with computers, from the simple touch of the mouse to the creation of their own handout. This training helped individuals to reduce their social vulnerability from the qualification with basic informatics.
\end{abstract}

Resumo. O pensamento computacional contribui para o desenvolvimento das competências adjacentes do indivíduo. Em nossa pesquisa, o pensamento computacional pode ser visto como um meio para auxiliar no processo de resolver problemas e aprender sobre o uso da tecnologia. Este trabalho tem como objetivo principal propor o uso de ferramentas computacionais para a capacitação da população migrante de origem haitiana e senegalesa na cidade do Rio Grande/RS. Os resultados deste estudo nos possibilitou observar o avanço dos estudantes com informática, desde o simples toque ao mouse até a criação de uma apostila própria. Esta formação auxiliou os indivíduos a reduzir sua vulnerabilidade social a partir da qualificação com informática básica.

\section{Introdução}

Desafios que demandam novas abordagens para serem resolvidos estão surgindo das constantes transformações da sociedade e da introdução de sistemas computacionais cada vez mais complexos. Segundo [Jonassen 2004], a aprendizagem provém de problemas que precisam ser resolvidos e do fato que os alunos aprendem e compreendem enquanto estão resolvendo os desafios. Neste contexto, o pensamento computacional pode ser visto como uma forma de resolver problemas, projetar sistemas e entender o comportamento humano. O pensamento computacional também é definido como a capacidade que um indivíduo tem para desencadear um processo de elaboração e solução de problemas [Wing 2006].

A lógica de programação é um dos saberes fundamentais para a construção do pensamento computacional, permitindo ao aprendiz fazer uma articulação coerente das informações em uma sequência lógica que possibilite a resolução de problemas [Ramos 2014]. No entanto, este saber, na maioria das vezes, é ensinado de forma isolada, sem contextualização e sem correlação com os conceitos de outras áreas de conhecimento, 
o que pode prejudicar o processo de aprendizado e a compreensão da aplicabilidade deste conceito no cotidiano do aluno.

Neste contexto, o pensamento computacional pode ser visto como uma forma de resolver problemas, projetar sistemas e entender o comportamento humano. O pensamento computacional pode ser aplicado para resolver problemas em diversas áreas, o que o torna uma habilidade essencial na formação básica de profissionais de todas as áreas, não apenas para estudantes de Computação [Wing 2006]. No entanto, o processo de aprendizagem destes conceitos é desafiador, apresentado dificuldades em vários aspectos tanto da perspectiva do professor quanto do aluno como: escolha do método, da técnica e dos aspectos pedagógicos a serem utilizados neste processo.

O pensamento computacional auxilia no desenvolvimento das competências adjacentes do aprendiz como: (i) o pensamento abstrato, utilização de diferentes níveis de subjetividade para compreender o problema; (ii) pensamento algorítmico, demonstração de soluções de problemas em diferentes passos de forma a encontrar a resposta mais eficiente e eficaz; (iii) pensamento lógico, formulação e eliminação de hipóteses; (iv) pensamento dimensionável, divisão de um problema em pequenas partes ou composição dessas partes para formular uma solução complexa [Andrade et al. 2013]. Assim, tornase evidente o potencial transformador social da computação, capaz de alcançar resultados que vão além ao seu âmbito técnico, contribuindo para a formação de indivíduos capazes de utilizar o raciocínio lógico para solucionar problemas nas mais diversas áreas da vida cotidiana. No cenário nacional e internacional atual, uma das áreas nas quais pode-se utilizar tal ferramenta é a crise migratória. Especialmente na Europa, migrantes e refugiados originados principalmente de países africanos e asiáticos chegam diariamente ao velho continente. A falta de políticas e ações de recepção e integração gera graves problemas sociais como, por exemplo, a marginalização dos migrantes.

No Brasil, muito embora não se possa considerar a existência de uma crise migratória no patamar Europeu, existem centenas de milhares de migrantes, vindo de todos os continentes, e este número cresce com a chegada regular de novos migrantes. Localmente, de acordo com a pastoral do imigrante da igreja católica, temos na cidade do Rio Grande, centenas de migrantes vindos principalmente do Senegal e do Haiti, sendo iminente a chegada de imigrantes vindos também da Venezuela. Assim, o objetivo desse estudo é a capacitação da população migrante de Senegal e Haiti que vivem na cidade do Rio Grande/RS, ensinando algumas ferramentas de uso comum, passando por didáticas para melhor uso do computador até o ensino do pensamento computacional via o uso de algumas linguagens de programação.

Este artigo está estruturado da seguinte forma: Seção 2, descrevemos a fundamentação teórica; Seção 3, apresentamos a descrição da metodologia; Seção 4 apresentamos os resultados, por fim na Seção 5 destacamos as conclusões e os trabalhos futuros.

\section{Fundamentação Teórica}

Atualmente, a área de ensino de lógica de programação/pensamento computacional vem chamando muito a atenção da comunidade científica. Sua aplicação vai desde o ensino fundamental até o ensino superior (em áreas diversas da computação), mostrando sua grande aplicabilidade. Nessa seção, elencamos alguns trabalhos relacionados ao tema, 
dando ênfase à metodologia de aplicação adotada e ferramentas utilizadas.

O trabalho de [Silveira et al. 2009] apresenta uma metodologia para ensino de lógica em cursos superiores de administração e economia. A ferramenta utilizada foi o Visual Basic for Application, da Microsoft. A metodologia foi dividida em quatro etapas: estudo de lógica de maneira geral, a partir do entendimento de comandos E/OU, seguindo da resolução de problemas, da representação gráfica (fluxogramas) e finalizando com a linguagem de programação para estruturar o conhecimento. Pelos resultados, observouse que o ensino de lógica é aplicável em todas as áreas de conhecimento, desde que bem contextualizado.

Em [de Oliveira et al. 2014] é apresentado um curso de extensão para ensino de lógica no ensino fundamental (9o ano). A ferramenta utilizada foi o Scratch. A principal ideia foi desenvolver um jogo computacional ao final do curso, como forma a incentivo de permanência dos alunos no curso. Assim, a metodologia para desenvolvimento do curso foi o ensino dos conceitos básicos, a construção de animações simples e finalizando, um desafio aos alunos, de criação de um jogo (de livre escolha). Houve uma evasão mediana (33\%) e os pesquisadores consideraram o curso adequado ao nível dos alunos.

O trabalho de [Ramos and da Silva Teixeira 2015] apresenta a aplicação de um curso sobre o pensamento computacional em uma turma do ensino fundamental (5o ano), utilizando como ferramenta o Scratch. O trabalho apresenta um embasamento sobre os PCN (Parâmetros Curriculares Nacionais) e o ensino do pensamento computacional. O curso abordou questões de lógica e números binários, seguindo de desafios na ferramenta utilizada. Os autores perceberam que mesmo sendo um curso bastante introdutório, foi bem aceito pelos alunos e professores da escola, pois houve envolvimento dos professores e inter-relacionado aos conteúdos previstos.

A utilização do pensamento computacional em atividades do PIBID (Programa Institucional de Bolsas de Iniciação à Docência) foi apresentado por [Lima and De Sousa 2015]. Os alunos do programa implementaram atividades junto a turmas do 5o ano do ensino fundamental, utilizando a IDE (Integrated Development Environment) Portugol. Inicialmente, foram apresentados os conceitos básicos de lógica, seguindo de resolução de exercícios. Também foram utilizados objetos de aprendizagem online para motivar na resolução dos exercícios. A avaliação dos autores foi positiva, pois houve baixa evasão (menor que 20\%). Além disso, foram aplicadas avaliações (português, matemática e lógica) entre os alunos, antes e depois das atividades. Os alunos apresentaram expressiva melhora nas médias das avaliações.

O ensino do pensamento computacional em escolas públicas a nível médio é apresentado em [Silva et al. 2016]. O trabalho apresenta duas formas de trabalhar com o pensamento computacional: a computação desplugada (sem o uso do computador) e o uso da ferramenta LightBot (ferramenta que simula um vídeo game para o ensino de programação). O estudo foi realizado com uma turma do lo ano do ensino médio e envolveu três etapas: ensino dos conceitos básicos, uso da computação desplugada para melhor entendimento do raciocínio lógico e aplicação prática na ferramenta LightBot. Pelos resultados apresentados, houve grande motivação dos alunos durante a realização das atividades.

A partir de nossa busca na literatura é possível observar que existe uma am- 
pla gama de ferramentas computacionais para ensino do pensamento computacional. Também observou-se que que foram utilizadas outras técnicas computacionais para motivação no ensino dessa disciplina, como objetos de aprendizagem e computação desplugada. Contudo, em todos os trabalhos apresentados, sempre se inicia a formação com os conceitos básicos da área de lógica. A aplicação de questionários não foi realizada em todas as atividades, ficando a validação dos resultados comprometida.

Neste contexto torna-se importante a criação de ações que visem evitar a segregação étnica e a marginalização destes migrantes, promover a integração e colocação dos mesmos na sociedade local, valorizando a pessoa humana e evitando que sejam utilizados como mão de obra barata. Um exemplo deste tipo de ação é realizado na Áustria, através de um projeto chamado RefugeesCode ${ }^{1}$, no qual a computação é usada como ferramenta de integração dos migrantes que chegam aquele país. A ideia do presente trabalho inspira-se no RefugeesCodes, e o contato direto com uma das criadoras do projeto na Áustria permite uma troca de experiências que tende a beneficiar significativamente o presente estudo.

\section{Metodologia}

Este estudo buscou a análise do perfil da amostra, via questionários para que fosse possível analisar os níveis de formação dos indivíduos, bem como o interesse para os cursos de computação e disponibilidade de horário para frequentar o curso. A amostra foi composta por 20 alunos haitianos com idade entre 26 e 35 anos, sendo duas mulheres e 18 homens. Estes alunos estão no país cerca de 24 meses aproximadamente. O curso teve duração de 33 dias, sendo que cada aula ocorreu por um período de três horas.

Neste estudo, um curso de computação nos módulos básico e intermediário foi desenvolvido a partir do perfil dos alunos, bem como a duração de cada aula do curso. Este curso busca a integração e oportunidade de estágios em empresas de tecnologias para os indivíduos que participaram do estudo.

No primeiro dia de aula do curso foi aplicado um questionário inicial, para conhecer melhor os alunos, a idade deles, a cultura, se tinham algum conhecimento em algumas das ferramentas utilizadas, e também para ter uma base do que eles entendem como computação. Outro questionário foi aplicado no último dia de aula, para saber o quanto de conhecimento foi adquirido, opiniões positivas e negativas sobre curso e o que acreditavam ser necessário retomar, em um curso de recuperação.

A etapa inicial do curso contemplou o ensino do pacote office e da linguagem Scratch. Inicialmente, ensinou-se o básico da informática, promovendo atividades que melhorem a maneira de como eles utilizavam os computadores desde a digitação até o uso do mouse.

Para a aplicação do curso foi utilizado o laboratório disponibilizado pelo Instituto Federal de Educação, Ciência e Tecnologia do Rio Grande do Sul (IFRS - Campus Rio Grande). Nas máquinas foram instalados WPS Office ${ }^{2}$, onde foram utilizadas na primeira fase do curso as ferramentas WPS Writer, WPS Spreadsheet e WPS Presentation, e na

\footnotetext{
${ }^{1}$ http://www.refugeescode.at/

${ }^{2}$ https://www.wps.com
} 
segunda fase do curso o $\mathrm{Scratch}^{3}$. Também no curso de recuperação foi utilizado o Google Docs $^{4}$ e Planilhas 5 .

\section{Resultados e Análise}

No início do curso, eram duas turmas, dos haitianos no turno da tarde, e a dos senegaleses no turno da noite. Mas, infelizmente, não houve interesse dos alunos nas aulas noturnas, mesmo após reuniões com os mesmos, para tentar adequar um horário que ficasse melhor. Assim, a turma da noite foi cancelada. A outra turma iniciou com 20 haitianos e foi reduzindo progressivamente para 12 e finalizou com apenas 7 alunos. No entanto, não ficou claro em nossos estudos porque houve uma evasão tão grande dos alunos.

No questionário inicial, pode-se ser uma base de que as duas turmas não tinham conhecimento básico de informática, apesar de que os alunos possuírem celulares de boa qualidade e $50 \%$ deles possuíam computadores de boa qualidade. Contudo, sabiam utilizar apenas as redes sociais. No questionário final, os alunos escolheram três temas para curso de recuperação: informática básica, documento e planilha.

Em nosso instrumento, foi questionado se o curso melhorou o entendimento dos alunos em relação à informática básica, e a resposta da maioria dos alunos foi positiva, como pode ser observado na Figura 1. Mas, observando os alunos em aula, observou-se que eles ainda têm muita dificuldade em lidar com computador e as ferramentas. Em uma conversa com turma para saber o que melhorar, a grande reclamação deles foi a falta de uma apostila impressa. Contudo, pela falta de recursos, não foi confeccionada uma apostila em papel.

\section{7 respostas}
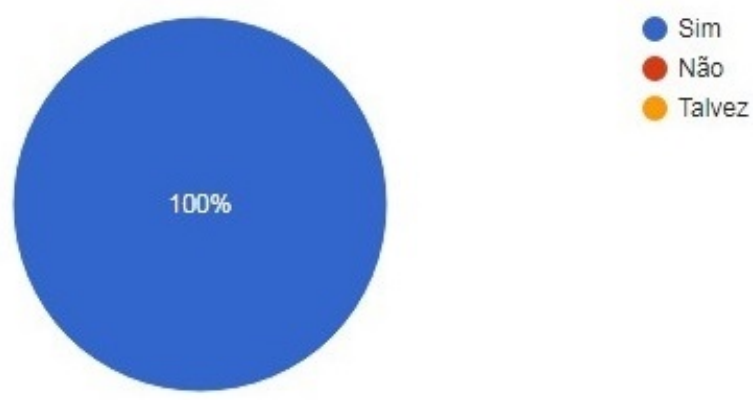

Figura 1. Exemplo de pergunta do questionário final da segunda fase do curso "Você acha que esta segunda fase do curso melhorou o seu entendimento sobre informática?"

Em relação ao questionamento relacionado às ferramentas que os alunos gostariam de treinar por mais tempo, a maioria respondeu que desejava utilizar por maior tempo as planilhas e os documentos, conforme pode ser observado na Figura 2. Acreditamos que esse interesse se deve pelo fato dos alunos poderem praticar mais a escrita e a utilização de fórmulas matemáticas, as quais são muito utilizadas no cotidiano destes indivíduos.

\footnotetext{
${ }^{3} \mathrm{https}: / /$ scratch.mit.edu

${ }^{4}$ https://www.google.com/docs/about/

${ }^{5} \mathrm{https} / / /$ www.google.com/sheets/about/
} 


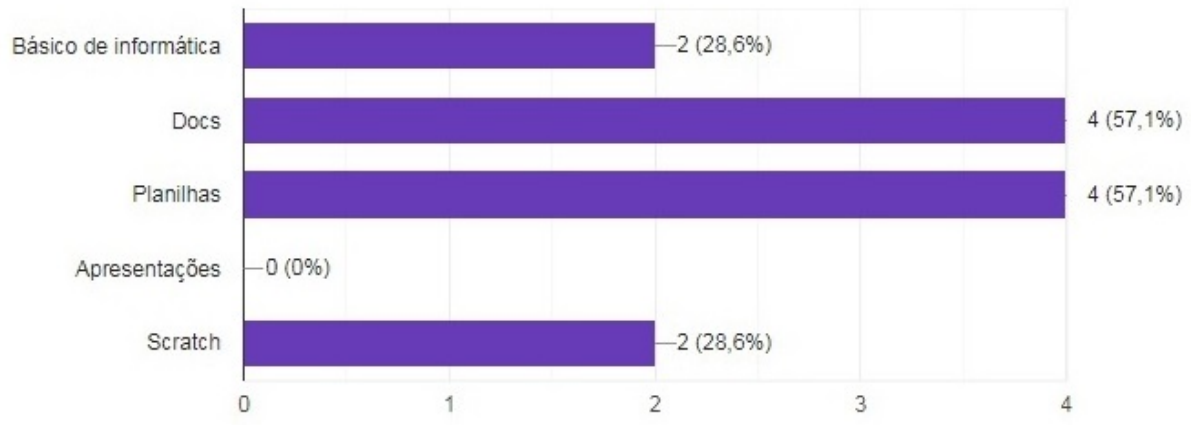

Figura 2. Exemplo de questão do questionário final da segunda fase do curso "Qual ferramenta você gostaria de rever?"

De forma a minimizar esse problema, foi sugerido que eles levarem um caderno e caneta para anotar, mas eles não se interessaram. A última tentativa foi utilizar o curso de recuperação para uma nova estratégia. Cada aluno iria fazer sua própria apostila utilizando o Google docs, apostila a cada aula iria sendo incrementada com novo conteúdo e disponibilizada para os alunos treinarem em casa também. Desta vez, 25\% dos alunos ainda fazem em casa e chegam na aula só para pedir ajuda na formatação, mas os outros $50 \%$ não se interessam nem fazer em casa, e os outros $25 \%$ por não ter um meio de fazer em casa, se esforçam a fazer na aula.

Em relação ao curso, é possível observar que os indivíduos falavam apenas francês e/ou crioulo e não dominavam a língua portuguesa brasileira, por isso o auxílio de um bolsista do curso de letras foi necessário para que os professores e alunos pudessem trocar informação. Os alunos tinham muita dificuldade para utilizar as duas mãos no teclado, digitação era feita, na maioria das vezes, clicando uma letra por vez. Em relação ao mouse, era difícil sua utilização pelos alunos, para que o manuseassem era necessário que o professor pegasse a mão do aluno e demonstrasse o funcionamento do mesmo. Essas dificuldades foram observadas durante o curso, sendo que quando o curso se aproximava do final observou-se que os alunos já utilizavam as duas mãos no teclado e conseguiam utilizar o mouse sozinhos, até mesmo ao chegar na aula, os aprendizes já se dispunham a ligar o computador e acessar o navegador.

Ao final do curso, a maioria dos alunos estavam tão interessados no curso que pediam ajuda para fazer seu currículo no computador, criar panfletos ou para formatar seu notebook, até dicas de informática foram solicitadas. Além disso, haviam dois casais no curso, um deles acabou desistindo, enquanto o outro, a esposa sempre que terminava primeiro que seu marido, tentava ajudá-lo a finalizar suas tarefas, sendo que ela tinha facilidade em aprender e em algumas oportunidades o professor acabava pedindo para que a aluna auxiliasse outros alunos, quando a turma ainda era grande. Por fim, os alunos ficaram muito motivados a realizar o curso, tanto que ao receber o certificado esboçavam sinais de alegria e satisfação.

Acreditamos que este trabalho proporcionou um maior esclarecimento sobre a computação, visibilidade sobre tema e a viabilidade de um estudo mais aprofundado. Além disso, o curso oportunizou aos indivíduos uma reflexão sobre a importância da 
computação no cotidiano deles, bem como despertou o interesse dos estudantes em aprofundar o conhecimento sobre o tema. Assim, observou-se que o pensamento computacional vai além do simples uso do computador, pois a computação propicia a aplicação dos princípios básicos da computação para resolução de problemas, de forma a expandir a capacidade do pensamento humano. Neste sentido, pensamos que é possível aplicar os princípios da ciência da computação sem, necessariamente, estar associado ao uso do computador.

\section{Considerações Finais}

O pensamento computacional pode auxiliar no desenvolvimento das competências adjacentes do aprendiz. Em nossa pesquisa, o pensamento computacional pode ser visto como um meio para auxiliar no processo de resolver problemas e aprender sobre o uso da tecnologia. Neste contexto, o objetivo desta pesquisa foi proporcionar a capacitação da população migrante de Senegal e Haiti que vivem na cidade do Rio Grande/RS, ensinando algumas ferramentas de uso comum, passando por didáticas para melhor uso do computador até o ensino do pensamento computacional via o uso de algumas linguagens de programação.

Este estudo buscou a análise do perfil dos indivíduos que participaram do curso para que fosse possível analisar os níveis de formação dos mesmos, bem como o interesse para os cursos de computação e disponibilidade de horário para frequentar o curso.

Nossa análise nos permitiu avaliar que inicialmente os alunos tinham pouco conhecimento do computador e dos aspectos básicos da computação como utilizar o teclado e mouse. Além disso, foi possível observar que embora tenha havido uma grande evasão do curso, os alunos que permaneceram se mantiveram motivados e ao final curso buscaram utilizar o seu novo conhecimento em computação para construir seus currículos e aprender novas técnicas de informática.

Por fim, a cada aula ministrada, foi possível aprender um pouco mais da cultura dos indivíduos que participaram do curso, sendo ela um novo desafio, do qual os pesquisadores tinham como objetivo manter os alunos motivados a aprender. Como trabalhos futuros pretendemos proporcionar novos cursos para que os alunos tenham maior conhecimento de computação, fazendo uso da computação desplugada para mostrar que o pensamento computacional está ligado a maioria das ações do cotidiano.

\section{Referências}

Andrade, D., Carvalho, T., Silveira, J., Cavalheiro, S., Foss, L., Fleischmann, A. M., Aguiar, M., and Reiser, R. (2013). Proposta de atividades para o desenvolvimento do pensamento computacional no ensino fundamental. In Anais do Workshop de Informática na Escola, volume 1, page 169.

de Oliveira, M., de Souza, A., Ferreira, A., and Barreiros, E. (2014). Ensino de lógica de programação no ensino fundamental utilizando o scratch: um relato de experiência. In Anais do XXII Workshop sobre Educação em Computação, pages 239-248. SBC.

Jonassen, D. H. (2004). Learning to solve problems: An instructional design guide, volume 6. John Wiley \& Sons. 
Lima, Á. C. and De Sousa, D. F. (2015). Desenvolvimento do raciocínio lógico e algoritmo através do programa institucional de bolsas de iniciação à docência no ensino fundamental. In Anais dos Workshops do Congresso Brasileiro de Informática na Educação, volume 4, page 1379.

Ramos, F. and da Silva Teixeira, L. (2015). Significaçao da aprendizagem através do pensamento computacional no ensino médio: uma experiência com scratch. Anais do Workshop de Informática na Escola, 21:217.

Ramos, H. d. A. (2014). Pensamento computacional na educação básica: uma proposta de aplicação pedagógica para alunos do quinto ano do ensino fundamental do distrito federal. Monografia do curso de Licenciatura em Computação. Universidade de Brasília.

Silva, V., Souza, A., and Morais, D. (2016). Pensamento computacional: Um relato de práticas pedagógicas para o ensino de computação em escolas públicas. Revista Tecnologias na Educação. Ano, 8.

Silveira, D. S. D., Loiola, E. M., and Ferreira, S. B. L. (2009). Uma metodologia de ensino de lógica aplicada em cursos de ciências humanas. RAM. Revista de Administração Mackenzie, 10(2):164-180.

Wing, J. M. (2006). Computational thinking. Communications of the ACM, 49(3):33-35. 